\title{
POSTHUMOUS PRESENTATION \\ OF THE 1971 KARL F. MEYER AWARD
}

Lieutenant-Colonel W. G. LISTON, C.I.E., M.D., D.P.H., I.M.S.

American Veterinary Epidemiology Society

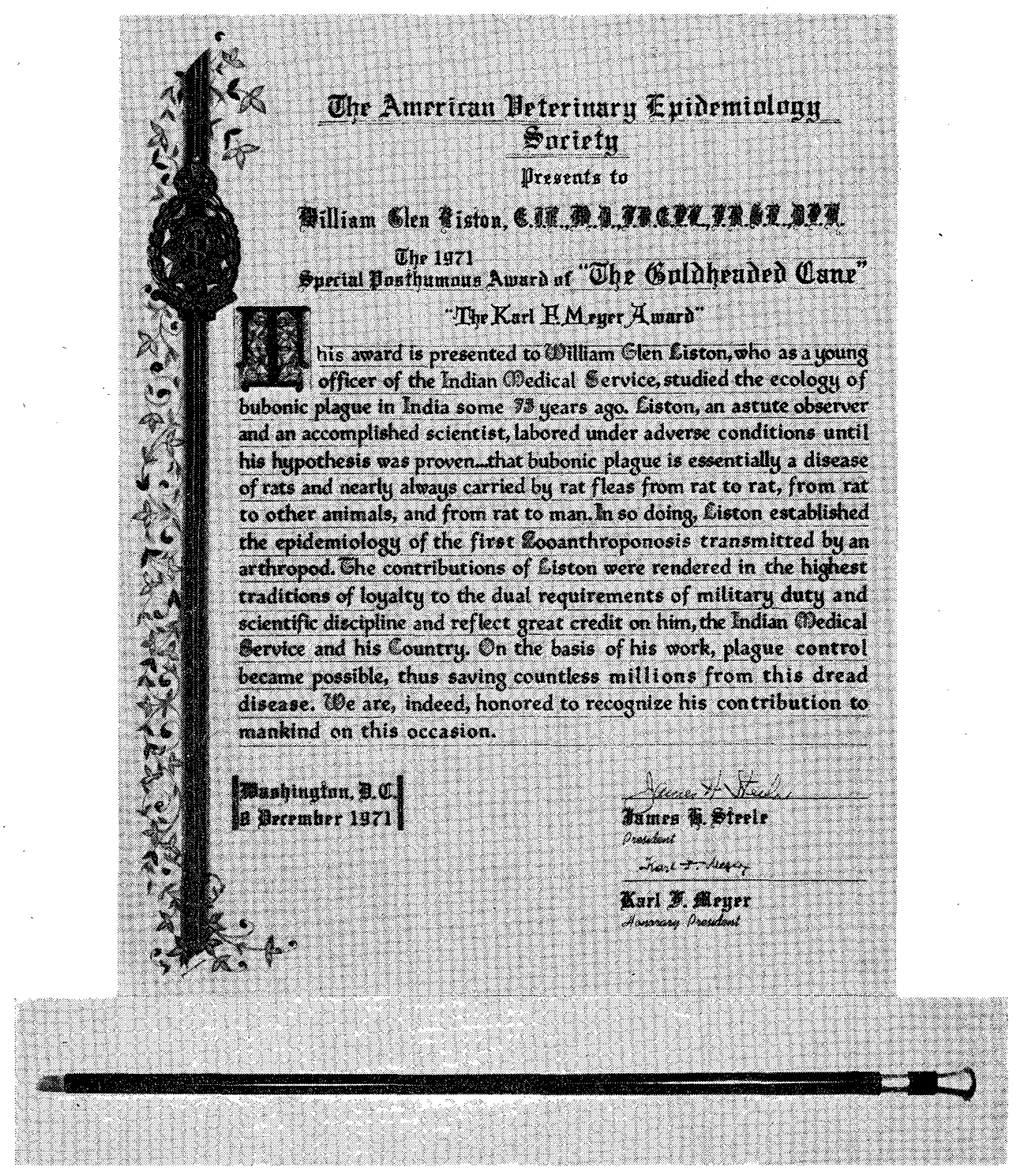

THE Karl F. Meyer Award was founded in 1964 by the American Veterinary Epidemiology Society to recognise distinguished work in veterinary epidemiology, and was 
named after the first receipient now Honorary President of the Society. The award consists of a gold-headed cane.

The 1971 award was accorded to Lieutenant-Colonel W. G. Liston, C.I.E., M.D., D.P.H., I.M.S., in recognition of his work in establishing the transmission of bubonic plague from rats to man by the rat flea Xenopsylla cheopis. Presentation of the award was by Doctor Karl F. Meyer at a special posthumous presentation at the Walter Reed Army Institute of Research, Washington, D.C., U.S.A. on 8 December 1971. The gold-headed cane was accepted on behalf of the late Lieutenant-Colonel Liston by Colonel H. W. Whitcher, O.B.E., T.D., Late R.A.M.C. representing the DirectorGeneral of Army Medical Services. A sheepskin scroll citing Lieutenant-Colonel Liston's accomplishments was also presented.

\section{ADDRESS BY DOCTOR KARL F. MEYER}

General Vorder Bruegge, Colonel Buescher, Colonel Whitcher, Dr. Steele, ladies and gentlemen:

We are assembled here in the George Miller Sternberg Hall of the Walter Reed Army Medical Center which commemorates two great military medical scientists, and so it is particularly fitting that we recognize posthumously another medical officer, who served in the elite ranks of one of our oldest allies. I am privileged to present historical documentary evidence that the candidate for the award discovered and proved that plague control is virtually synonymous with flea control.

Just 75 years ago, plague invaded the port of Bombay, India. Spreading rapidly, the dread disease eventually claimed approximately $13,000,000$ lives before it disappeared. Simond, working in 1898 in Bombay, had incriminated the flea as the vector of Pasteurella pestis (Yersinia pestis), but his theory was ridiculed by all. Fortunately, there was on the spot a young officer of the Indian Medical Service who, in the words of Bannerman, "saw the possibility, collected the facts and conducted the experiments that placed the despised flea hypothesis in quite a new light." Many of this officer's early studies were published in rather obscure journals not readily available to those who attempted to review the history of plague. Since the accounts of such reviewers have not dealt kindly with our candidate, it is now the proper occasion to put the essential facts in valid perspective.

Born on 30 July 1873, in Secunderabad, India, the candidate was the son of an Army chaplain. He was educated at Watson College, Edinburgh, as well as at the Albany Academy in Glasgow, and received his Bachelor of Medicine degree with honors at Glasgow University in 1897. Subsequently he entered the Indian Medical Services in 1898 and was assigned to the Army Medical School at Netley to be trained as a medical officer for duty in the Colonies. His curriculum included up-to-date courses on bacteriology, pathology, and parasitology. At this time, the pioneer studies of Kilbourne and Smith on Texas cattle fever, those of Ross on avian malaria, and the investigations of Grassi on human malaria were just attracting attention. Upon graduating fifth in the class and receiving the Pathology prize, the candidate was sent out to India, arriving in Bombay on 5 December 1898. A Royal Indian Plague Commission had been appointed to study all aspects of the problem, particularly how the disease was transmitted. Professor A. E. Wright, a member of the Commission and Instructor at Netley, employed the candidate as an assistant and assigned him to the Plague Research Laboratory in 
Bombay to study such factors as the sterility of Haffkine's plague vaccine, the survival of $P$. pestis on grain and other substances, the isolation of the plague bacillus from foodstuffs and from rats and patients, and the disinfection of grain and the premises where plague might occur. The hearings held by this commission were very thorough, delving into every possible aspect, although the measures which were currently in use to control the disease were both ineffective and unpopular. In view of his position, the candidate was able to formulate a clear picture of what was known and what was unknown about plague from the voluminous testimony.

The role of the rat was duly examined, and while it was certain that human beings and rats were infected and killed by the same agent, the connection between the disease in man and in rats was not clear. It is true that workers of the German Plague Commission had isolated the plague bacillus from fleas; and also, Simond in preliminary experiments had incriminated fleas as vectors on epidemiological grounds, but the commission rejected this evidence as so inconclusive as to be hardly worth consideration. On the basis of its findings, the commission announced that blood-sucking insects had no significant part in the transmission of the plague bacillus. Simond's brilliant thesis intrigued the young officer, and he began studying fleas as he had previously studied mosquitoes.

Upon the commission's departure from India, the candidate was released from duty at the plague laboratory and assigned to Ellichput near Berar in the Upper Deccan to work on famine relief. He remained there in this capacity for a year, and able to put his training at Netley to good use. His studies in this area afforded him an opportunity to write interesting articles on malarial mosquitoes and the use of serological tests in the diagnosis of infections, as well as other medical problems.

In 1901 the candidate returned to the plague laboratory in Bombay to assist L. T. C. Bannerman, the superintendent of the laboratory, in producing plague vaccine. $\mathrm{He}$ continued to exercise his interest in malaria and in the mosquitoes which transmitted the parasite. That same year, he published a paper on mosquitoes, and assisted $\mathbf{S}$. $\mathbf{P}$. James in preparing a beautifully illustrated monograph on Indian Anophelinae which appeared in 1904 and proved of great value to other investigators of malaria in India. Utilizing this entomological background, he began to collect the material that was to lead resolution of the problem of transmission of the plague bacillus.

In January 1902, the candidate was sent back to Netley to take a special course in bacteriology and hygiene. While in England, he obtained his M.D. with honors and was awarded the Bellahouston gold medal from Glasgow University for his thesis on malaria. At this time, he took a most significant step: He approached the Honorable Charles Rothschild, the world renowned siphonapterist with a collection of fleas he had gathered in Bombay. Rothschild was quick to point out the differences between fleas inhabiting cats, dogs, rats and man, and the fact that the fleas the candidate collected from rats closely resembled the newly described Pulex pallidus (Pulex cheopis, now Xenopsylla cheopis). Realizing the importance of ascertaining the variety of rat involved in the epidemiology of plague, the young officer became familiar with the taxonomy of the rat reservoirs in Bombay under the expert guidance of Oldfield Thomas at the British Museum. In 1903, again reporting to the plague laboratory at Parel for duty, the candiate was now certain that fleas were responsible for human plague infections. The question was how to prove it. He was faced with two pressing problems - the questions 
raised by his immediate superiors, the Director-in-Chief W. M. Haffkine and the superintendent Major Bannerman. The latter's point was quite simple: many of the patients in the plague wards were infested with fleas, yet the physicians and nurses attending these people were themselves but rarely infected with plague. Did this not invalidate the flea hypothesis?

The objections of Haffkine presented even more difficulties. Simond had, of course, demonstrated that fleas could carry the plague bacillis between sick and healthy rats; but in Haffkine's opinion, the fact that Simond had not been 100 per cent successful nullified the entire matter. Further, Haffkine had suggested that two of his colleagues on the Bombay scientific commission should study the role of insects. One of these colleagues, E. H. Hankin, in 1897 studied ants; another, Surveyor, investigated miscellaneous bugs. Their results, however, indicated that although these insects might become contaminated, they were of no importance. Haffkine was not favourably disposed towards the candidate, and there was considerable tension between the two, resulting on at least one occasion in the young man's temporary transfer from the plague laboratory.

Other influential voices were raised against the flea hypothesis. G. H. F. Nuttal and R. Koch had failed in experiments on transmission of the disease and had concluded that transmission of the plague bacillus by fleas was of no significance. Perhaps influenced by the so-called evidence, one individual, B. Galli Valeric, in 1900 offered himself as an experimental subject for flea experiments.

All the "expert opinion", therefore, seemed conclusive and the flea hypothesis was the subject of rather derisive editorials in the authoritative Indian Medical Gazette. No one had noticed the small papers of Gauthier and Raybaud (1904) or of Zirolia (1902), in which data confirming Simond's theory was presented.

One indeed must be brave to go against the current of expert opinion! The candidate, however, was sure of his convictions and undaunted by the forces arrayed against him. On Friday the 13th of February, 1903, he presented his paper, "Some observations on fleas and some facts which would appear to associate these insects with the spread of plague" at a meeting of the Bombay Medical and Physical Society. In this modest paper, he summarized his conclusions and set forth his goal of proving that the flea was involved in the transmission of the plague bacillus. Vermin-infested houses, clothing and grain were associated with plague in man and rats. Bacteriological evidence revealed that the natural infection of soil, clothing and grain disappears within a few days. Moreover, rats could live and thrive on grain that was grossly contaminated with plague cultures. A missing link was obviously indicated, and the flea was that missing link. When the seasonal incidence of plague was studied, the disease was found to be most prevalent when rat fleas were most abundant. Illustrations delineating the taxonomic differences between the diverse fleas of Bombay accompanied the verbal presentation. This paper, also published in the Indian Lancet, attracted considerable attention. Of particular interest was an editorial in the Indian Medical Gazette expressing satisfaction that the question of flea transmission was now in the capable hands of an officer who would settle the matter once and for all.

The first breakthrough occurred in March 1903, when the candidate received reports that some guinea pigs had been found dead in a Bombay zoo. Examining these animals, he discovered they had died of plague and were infested with plague-infected rat fleas 
(Xenopsylla cheopis). Apparently, the guinea pigs were suitable hosts for rat fleas, and the fleas were attracted to them. Thus he conceived the idea of utilizing pigs to attract such fleas as might be encountered in the plague-ridden chawls and tenements of Bombay. The residents of these dwellings were often infected with plague, yet no evidence of the manner of infection had been discovered when the premises were examined and disinfected. However, guinea pigs which were released in these quarters and allowed to run freely throughout the suspected rooms rapidly became infested with rat fleas. Apparently these rat fleas had been forced to seek another host when their normal ones, the rats, were not available. Several of the fleas collected in this manner were found to be infected with the plague bacillus, and some of the exposed sentinel guinea pigs used in the experiments died of plague.

Other observations served to fill in gaps in the picture: Persons dwellings in areas where rats began to die (the so-called "rat-fall" areas) were suddenly bothered by fleas. These fleas were identified by the candidate as rat fleas. Some of the individuals who had been bothered by the fleas subsequently developed plague, and these fleas were plague-infected.

The candidate called attention to yet another fact which helped to complete the chain of circumstantial evidence against the flea: Individuals working in shops which sold oil or in sheds where oil was stored were seldom infected with plague. No matter how furiously the epidemic raged in their immediate vicinity, these persons displayed a curious immunity. This immunity was easily explained by the candidate, who noted that the bodies of such workers were usually coated with oil, and oil had been demonstrated to be an effective flea-repellent.

By making extensive collections of the fleas found in the clothing and on the persons of the patients in the plague wards, he proved that the fleas infesting the plague wards were almost exclusively human fleas, not the rat flea. Thus Bannerman's reservation on the validity of the flea hypothesis was negated - the rat fiea was obviously the agent by which the plague bacillus was conveyed from sick and dying rats to healthy human beings. The significance of the initial lesion of plague, the so-called "phlycténules" (vesicle) of Simond, was recognized. It was the site of inoculation of the plague bacillus where the flea-bite occurred.

Haffkine's objections to the flea transmission theory were in part resolved by simple experiments. Together with J.C.S. Elkington, the candidate worked in the laboratory on the experimental infection of rats with the plague bacillus via flea-bite. They were successful. The methods they employed were similar to those used today. A rat flea was fed upon a rat dying of plague. The flea was then held in a test tube and later allowed to feed upon a healthy rat. This procedure was rendered slightly safer by applying the open end of the tube containing the infected flea to the shaven abdomen of the healthy rat. The healthy rat, in a good number of instances. died of plague after the flea had fed upon it.

Yet Haffkine's objections could still prevail so long as this scientist insisted on either 100 per cent success or nothing. Today such a demand is recognized as unreasonable. Those who have worked with infected fleas know that even under the best circumstances, complete success is rare in plague transmission experiments involving individual fleas given but brief opportunities to feed. In several trials, the candidates suspended cages of rats over pans of germicide which were then infested with infected rat fleas. Only 
partial success was achieved. Many fleas were lost when they left the rat and fell into the disinfectant. Bannerman, now a sympathetic supporter, ordered the construction of strictly rat- and flea-proof blocks of huts or "go-downs" in which flea experiments simulating natural conditions as closely as possible could be conducted.

Benefiting from his work on malaria, the candidate proceeded to examine fleas to determine the fate of the plague bacilli ingested by the insects. He dissected fleas and found the bacilli in their stomachs. In addition, he prepared sections of fleas and described the insect's proventriculus (the sucking organ, in his nomenclature), observing the accumulation of plague bacilli in this compartment. Likewise he noted the multiplication of bacilli in " the rich pablum" medium of ingested blood. Unfortunately, he did not examine fleas which had been held for sufficient time following infection, nor did he note the formation of the "proventricular block", which was described in 1913 and is now recognized as the mechanism by which fleas may act as biological vectors of the plague bacillus. These early histological studies unquestionably provided a sound foundation for the work of later investigators.

Other developments hampered the future plague work of the candidate, and the flea studies had to be decreased while he was under Bannerman's guidance. The mass manufacture of a safe plague vaccine was re-organized following the Mulkowal disaster in 1902. But more important, the flea work had attracted the attention of the scientific community.

Dr. C. J. Martin of the Lister Institute approached the Government of India in the fall of 1904 with the proposition that a Plague Research Commission to be appointed by the Advisory Committee on Plague in India be formed to study the disease. Agreement was quickly obtained and the services of the candidate were specifically requested. Martin arrived in Bombay in April 1905, just as the flea- and rat-proof buildings were near completion. The entire project was turned over to the Plague Commission, of which the candidate was a member. Because of the complex nature of the study and the sizable staff which was to be employed, it was decided that the findings would be published anonymously. As a result, individual contributions to the outstanding work of the commission are difficult to ascertain, but thorough analysis reveals the experienced and sure hand of the candidate in many of the reports.

The use of his flea- and rat-proof rooms to provide conclusive evidence that fleas transmit the plague bacillus, the ideas of the candidate concerning the anatomy of the rat flea, the significance of the various species of rat reservoirs, and the relationship of the epizootic to the epidemic were thoroughly investigated experimentally on a large scale by the workers on the Advisory Commitiee. Generally overlooked is the important fact that shortly after the candidate had read and illustrated his significant paper "Plague, rats and fleas" at a meeting of the Bombay Natural History Society in November 1904-67 years ago-the role of the flea in plague became established throughout India. In contrast to those of preceding issues, the pages of the Indian Medical Gazette soon abounded with contributions recognizing the soundness of his flea work and its epidemiologic implications and conclusions. A champion of the rat-flea theory wrote of the candidate's paper: "We at length seem to be in a position to understand the Psalmist's phrase, "The pestilence which walketh in darkness".

In reviewing the evolution of our modern concept of the epidemiology of bubonic plague occurring over the past 75 years, we have achieved a sound perspective. With 
the passage of time, individual discoveries partly submerged in the Plague Commission reports as well as the Milroy lectures by the candidate in 1924 have been weighed, evaluated and assigned their proper place. In this context, a picture of first the young and then the mature candidate emerges-an always friendly, helpful man of wide interests and culture. Pre-eminent in his own sphere as an astute observer, scientist, bacteriologist, and research worker, he brought his vast knowledge and ripe experience to bear upon problems of every-day medical practice and public health. Convinced of the validity of his observations and possessed of a robust courage, he persisted under adverse circumstances until his hypothesis was proven. There is overwhelming evidence in the history of research concerning the transmission of plague that the candidate proved bubonic plague to be essentially a disease of rats, nearly always carried by rat-fleas from rat to rat and from rat to man. Without fleas, there is no transmission of the plague bacillus from rat to man, and epidemics of bubonic plague are not possible.

The American Veterinary Epidemiology Society, inspired by critical analysis of the historical record, is honoured to recognize this inspiring exemplary pioneer posthumously with The Gold-Headed Cane Award. In classical experiments, he was the first to elucidate the epidemiology of an anthropozoonosis caused by a bacterial parasite interchanged between other mammals and man through a complex ecological interplay involving an arthropod.

The world will remember: WILLIAM GLEN LISTON, C.I.E., M.D., D.P.H., Lieutenant-Colonel I.M.S., 30 July 1873-18 October 1950, who gave his best to humanity.

\section{REPLY BY COLONEL H. W. WHITCHER}

General Sir Norman Talbot, the Director-General of the British Army Medical Services, unable to be present today asked me to stand in for him as his personal representative. This I am happy to do.

Over the past 6 years I have been privileged to watch at close quarters the superb care given by all members of your Medical Department to the sick and wounded of your Armed Forces, and whoever else may have been entrusted to their care.

The standard of excellence set has been so high and is now so well recognised by the general population in the United States of America that nothing less will be acceptable in the future whether within the military or the civilian sphere. Other countries have watched very closely and have learnt from you. They too, will be required by their general public to achieve the high standards you have demonstrated possible.

This ceremony today has relevance. Behind the medical personnel in the field of battle or in the hospital wards and laboratories have always stood many workers determined to make their own personal contribution. Only a few get known.

William Beaumont was such a one

Ross was such a one

Walter Reed was such a one, and

Liston was such a one

They were men who achieved results by careful observation and clear thinking. They took time to consider logically what they observed and well heeded the adage to "Beware of the barrenness of a busy life.". 
I have been privileged to serve with the I.M.S. and to hold I.M.S. posts. I have served in many Cantonments in which Liston worked. He did not work in isolation on the problems of plague alone but with the help of many of the fine men to be found on the Indian Sub-Continent, the Sepoys, Naiks, Havildars, Jemadars, Subadhars. I am happy to see present Major-General Naidu, the Indian Military Attache and to know that he will pass back these sentiments to his Surgeon-General.

It is the intention of my Director-General that the award will be placed in a prominent position in our Royal Army Medical College in London, to serve as an inspiration and a reminder to all ranks that any one man may, by careful intelligent work, reach conclusions and establish facts of lasting and incalculable benefit to mankind.

Doctor Meyer, I thank you for making possible this very fine memorial to the late Lieutenant-Colonel Glen Liston.

\section{ACADEMIC ACHIEVEMENTS}

M.D.

Colonel R. A. Dunbar-Miller, M.B., B.S., F.R.C.P.(Edin.), F.R.C.P. (Glas.), F.R.F.P.S., M.R.C.P., D.P.M., D.T.M.\&H., late R.A.M.C.

F.R.C.S.

MAJOR M. R. PEACOCK, M.B., Ch.B., D.L.O., R.A.M.C.

M.R.C.P. (U.K.) LIEUTENANT-Colonel J. C. MOORSHÉAD, M.B., B.S., D.T.M.\&H., D.C.H., R.A.M.C.

M.F.C.M. Brigadier A. B. Dick, T.D., M.B., Ch.B., D.T.M.\&H., late R.A.M.C.

D.Obst. R.C.O.G. Major M. F. HADOKE, M.B., B.S., M.R.C.S., L.R.C.P., R.A.M.C. CaPTain P. E. P. Michael, M.B., B.Ch., B.A.o., R.A.M.C. CAPTAIN M. KiRWAN, L.R.C.P.I. \& L.M., L.R.C.S.I., \& L.M., R.A.M.C.

D.M.R.D. MAJOR J. A. BARR, B.A., M.B., B.S., R.A.M.C.

D.C.H.' Lieutenant-Colonel T. G. Rees-Jones, M.R.C.G.P., M.R.C.S., L.R.C.P., D.obst. R.c.o.G., R.A.M.C. MAJOR J. E. Findlow, M.B., ch.B., M.R.C.P., R.A.M.C. CAPTAIN E. J. M. Cantillon, M.B., B.Ch., B.A.o., R.A.M.C. Captain C. O. Holme, M.A., M.B, B.Chir., R.A.M.C. CAPTAIN R. ROBERTSON, M.B., Ch.B., R.A.M.C:

M.Sc (in Pros- Lieutenant-Colonel R. Coulthard, B.D.s., R.A.d.c. Lieutenant-Colonel R. thetic Dentistry) DOCHERTY, L.D.S., R.A.D.C.

Erratum: Volume 118, No. 4, October 1972, Page 198, against Captain Blackman, Glen, Melling and Plant, for D.Phys.Med read D.P.M.

\section{NOTICE}

Please note that R.A.M.C. Stable Belts and the R.A.M.C. Flag are no longer obtainable from the P.R.I. R.A.M.C. Training Centre.

These items can now be obtained from:--

R.A.M.C. Historical Museum,

R.A.M.C. Training Centre, Keogh Barracks,

Ash Vale, Aldershot, Hants.

R.A.M.C. Stable Belts $£ 1.00$ each. R.A.M.C. Flag $£ 3.00$ each.

Cheques/Postal Orders should be made payable to the R.A.M.C. Historical Museum Trust Fund. 